\title{
The Effect of Various Passing Exercises and Ankle Coordination on the Accuracy of Short Passing in Football
}

\author{
Ega Gian Vembiarto \\ Master Program in Sport Sciences \\ Universitas Negeri Yogyakarta \\ Sleman, Yogyakarta \\ egagian18@gmail.com
}

\author{
Lismadiana \\ Faculty of Sport Sciences \\ Universitas NegeriYogyakarta \\ Sleman, Yogyakarta \\ lismadiana@uny.ac.id
}

\begin{abstract}
The difference between the various passing training methods and the accuracy of short passing; (2) The difference between ability and height of the foot in terms of the accuracy of short passing; and (3) the interaction method of training and accurate coordination of short passing. $2 \times 2$ factorial method. Results. (1) There is a significant difference between varied passing and fixed training when we talk about the accuracy of short passing. The method of various training passes positions is better than various training positions for the accuracy of short passing. (2) There exists a significant difference in quality and accuracy for short legs when it comes to the accuracy of short passing time. Students with higher feet are better than the students with narrow legs when working on the accuracy of short passing. (3) There is a significant relationship between varied and fixed passing training methods and short ankle (high and low) to the accuracy of short passing.
\end{abstract}

Keywords—varied passing training methods, coordination, short passing accuracy

\section{INTRODUCTION}

In the game of football, passing the ball is an individual technical skill that every player must understand and get acquainted with. Playing the ball must be accompanied by the ability to free oneself from his opponents, protecting the ball while doing a run and forward deceptive movements. The ball must remain in control. The number of ball possession marked by a large number of passes in Spanish La Liga 2008/2009 season was positively correlated in winning the match. Ball possession is to a large extent dependent on the quality and quantity of passing in a team. This means that the passing accuracy of a team is a great determinant factor to the success of the team [1].

Basically, playing good soccer is attributed to absolutely good passing. Roughly $80 \%$ of the game has to do with the giving and receiving of passes. The pass must be realized at the right time by the player to the teammate. For a good play, passing skills are important. The range of play is negatively affected when a player unable to distribute passes to a teammate in open space, bend a ball around opponents, or chip a ball over a wall of defenders. It is extremely difficult to move the ball through the middle of the field without good passing skills. Your team should spend much time developing passing technique [2].

Ball possession percentages of the successful teams vary between $50.32 \%$ and $56.71 \%$. Among 17102 passing attempts of successful teams, it was observed that 13378 were successful, having a high rate of passing success such as $78.22 \%$. As a result, in the organizations such as the World Cup in which elite athletes participated, successful teams had of the ball possession. that having the ball in midfield and attacking region and passing attempt, successful passes distributed at a high level are the most basic principles that bring about success [3].

From the quotation above, it is clear that passing is very important to open a room that is balanced with good ball control.Besides, a good, strong, and directed pass can support goal creation. To obtain good passing skills, Footballers must practice regularly and repeatedly. Reportedly, approximately $80 \%$ of goals are a short sequence of approximately three passes or less [4].

Based on observations and interviews with PORDA Sleman Yogyakarta football coach, there were players who had not still get it right in distributing short passing to their friends. Some Players stay too far in the side or forward when giving passes, making it difficult for teammates/ recipients to reach the ball. The teacher/trainer stated that players who made 10 passing attempts, on average fail to lead correctly to their teammates. This could have a negative impact on the team during the game because if the passes are not well distributed, it will be easy for the opponent to win. If a pass is too wide or far from the reach of the foot, the ball will easily be lost due to difficulty in control. As a result, the ball will come out of the field. The trainer mentioned that there was already a training for the passing program but there still exists some difficulties. The passing training is also felt to be less when compared to the portion of other technical exercises. Thus, the coach hopes that each player will be able to do short passing well, with the right accuracy.

Other problems faced by the Yogyakarta PORDA players when passing are: (1) the foot focus is not aligned with the direction of the target or the tip of the foot towards the target, (2) the foot of the player with the ball possession is not rightly placed on the ball surface rather, it is placed on top of the ball, (3) body position is not balanced when kicking. Passing is most significant in the game of football, without neglecting the importance of other movements. The ability to pass a useful in defending the areas and building good attacks. Besides, assist also requires very important techniques, so remain in a good control by teammates. A good assist will 
bring an open direction and can control the game while building the defense and attacking strategies.

Overcoming this problem, it needs to be given an appropriate training method so that there will be an increase in the accuracy of short passing. The training method is the procedure and selecting method of the type of the exercise. It also involves it's to the level of complexity and difficulty [5]. The purpose of planning an exercise is to develop the skills and performance of athletes. The training method used is the method of varying passing exercises, fixed and changing positions. Variation in a fixed position passing training is a form of passing training which is done by forming a rectangle with varying passing directions but the position is always in the starting position. This exercise is done to improve the accuracy of short passing as well as to improve the ability to control the ball off by the players. This exercise is also done to support the player's ability to feel the ball when passing the ball to his teammate, how far the passing power is done based on the distance available. The advantage of this exercise is that it is very easy to perform because each player only directs the ball that will be passed to the partner who is always in his position, but this training model is less effective because the trainee easily experiences boredom, and lacks coordination between eyes and feet so that stimulation to be serious in doing the exercises will have an effect on improving the accuracy of short passing.

Varied passing training is a passing exercise done with several pairs. This exercise is almost the same as training through various positions. The difference is that in this practice, the players go through various positions needed by the teammates. This exercise does several things in passing by rotating clockwise. This exercise can also improve passing accuracy and ball feel. The problem is that this training model is difficult to implement because training children always require aiming at changing goals, but this exercise model will continue to motivate children to practice in their implementation. The results obtained will be maximized.

The accuracy of short passing, besides being influenced by external factors such as the training and ankle coordination, is also influenced by internal factors, namely cognitive, conative, and social. This opinion states that the results in football depend on psychomotor factors (strength, speed, endurance, flexibility, coordination, and accuracy), psychological factors (cognitive, conative, social structures), incentive structures, teaching and training methods, variations of external factors (field play, equipment, community, etc.), and error factors. The most important ability of the players because the successful completion of the situation in the game of football is mainly carried out by motor activities. During a match, better chances are on the side of players who have this factor in the optimal ratio [6].

Coordination is a complex necessary for high performance [7]. Coordination is the ability of the performer to integrate various types of body movement into specific patterns [8]. It is explained that coordination is the ability to perform certain pattern movements well. "Without good coordination skills, the athlete will have difficulty in performing techniques in harmony and stimulant, so that it looks flexible and easy" [9]. "Athletes with good coordination finds it easier to perform movement skill and spend less energy than athletes who have low coordination" [7]. Good coordination is also needed for accuracy, so it is necessary to perform regular and continuous ability training to facilitate the ability of a player to move, for better accuracy.

\section{RESULTS}

Hypotheses test will be presented sequentially, among others: (a) The difference in the effect of varies passing training methods on fixed positions and changes to the accuracy of short passing; (b) The difference in the effect of high ankle coordination skills and low ankle coordination skills on the accuracy of short passing; and (c) Interaction of training methods and coordination of the accuracy of short passing.

TABLE I. DESCRIPTIVE STATISTIC OF PRETEST AND POSTTEST SHORT PASSING ACCURACY DATA NORMALITY TEST IN THIS STUDY WAS THE KOLMOGOROV SMIRNOV METHOD. THE RESULTS OF THE DATA

\begin{tabular}{|l|l|c|c|}
\hline Coordination & Statistic & Pretest & Posttest \\
\hline \multirow{3}{*}{$\begin{array}{l}\text { High } \\
\text { A1B1) }\end{array}$} & Total & 10,00 & 14,00 \\
\cline { 2 - 4 } & Mean & 2,0000 & 2,8000 \\
\cline { 2 - 4 } & SD &, 70711 &, 83666 \\
\hline \multirow{2}{*}{$\begin{array}{l}\text { Low } \\
\text { A1B2) }\end{array}$} & Total & 19,00 & 29,00 \\
\cline { 2 - 4 } & Mean & 3,8000 & 5,8000 \\
\cline { 2 - 4 } & SD &, 83666 &, 83666 \\
\hline \multirow{2}{*}{$\begin{array}{l}\text { High } \\
\text { (A2B1) }\end{array}$} & Total & 23,00 & 42,00 \\
\cline { 2 - 4 } & Mean & 4,6000 & 8,4000 \\
\cline { 2 - 4 } & SD &, 54772 &, 89443 \\
\hline \multirow{2}{*}{$\begin{array}{l}\text { Low } \\
\text { (A2B2) }\end{array}$} & Total & 11,00 & 17,00 \\
\cline { 2 - 4 } & Mean & 2,2000 & 3,4000 \\
\cline { 2 - 4 } & SD &, 44721 &, 54772 \\
\hline
\end{tabular}

Normality test performed in each group of analysis were carried out using the SPSS version 20.0 for Windows software program with a significance level of $5 \%$ or 0.05 . Data summary is presented in Table:

TABLE II. NORMALITY TEST

\begin{tabular}{|l|c|c|}
\hline \multicolumn{1}{|c|}{ Data } & p & Explanation \\
\hline Pretest A1B1 & 0,759 & Normal \\
\hline Posttest A1B1 & 0,953 & Normal \\
\hline Pretest A2B1 & 0,510 & Normal \\
\hline Posttest A2B1 & 0,577 & Normal \\
\hline Pretest A1B2 & 0,953 & Normal \\
\hline Posttest A1B2 & 0,953 & Normal \\
\hline Pretest A2B2 & 0,214 & Normal \\
\hline Posttest A2B2 & 0,510 & Normal \\
\hline
\end{tabular}

Based on the statistical analysis of normality tests that have been carried out using the Kolmogorov Smirnov Z test, on all pretest and posttest data obtained from the data normality test the significance value of $p>0.05$, which means the data is normally distributed.

Homogeneity test is the equations of several samples which are homogeneous or not. The homogeneity test is intended to test the variance similarity between pretest and posttest. The homogeneity test in this study is the Levene Test. Homogeneity test results are presented in Table: 
TABLE III. HOMOGENEITY TEST

\begin{tabular}{|c|c|c|}
\hline Group & Sig. & Explanation \\
\hline Pretest & 0,610 & Homogeny \\
\hline Posttest & 0,362 & Homogeny \\
\hline
\end{tabular}

Based on the statistical analysis the homogeneity test has been carried out using the Levene Test, at the pretest-posttest score was obtained significance $p \geq 0.05$. This means that the data group has a homogeneous variant. Thus the population has homogeneous variants.

Hypothesis testing was carried out based on the results of data analysis and interpretation of two-way ANOVA analysis (ANOVA two-way). Hypothesis Test Results are presented in the table:

TABLE IV. ANOVA TEST

\begin{tabular}{|l|c|c|c|}
\hline \multicolumn{1}{|c|}{ Source } & $\begin{array}{c}\text { Type III } \\
\text { Sum of Squares }\end{array}$ & F & Sig. \\
\hline Training Method & 12.800 & 20.480 & .000 \\
\hline Coordination & 5.000 & 8.000 & .012 \\
\hline $\begin{array}{l}\text { Coordination } \\
\text { Training Method }\end{array}$ & 80.000 & 128.000 & .000 \\
\hline
\end{tabular}

Diagrams result from interactions between varied passing training methods fixed and changed positions and ankle coordination (high and low) on the accuracy of short passing can be seen in Figure below:

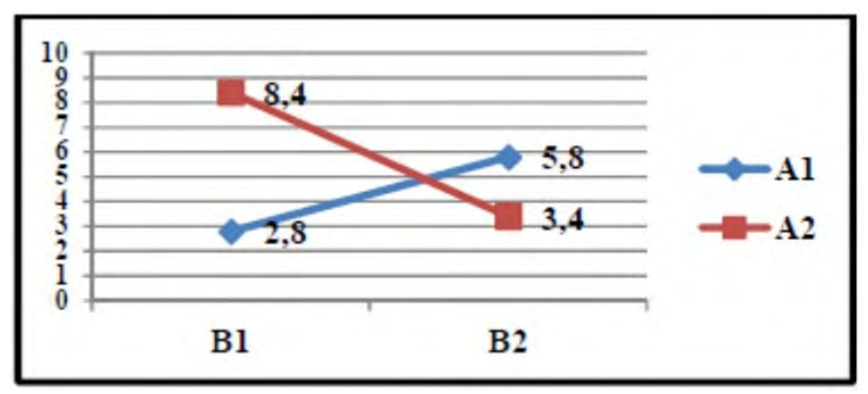

Fig. 1. Result of Interaction Between Varied Passing Exercise Methods Fixed and Changed Positions and Ankle Coordination (High and Low)

Based on the results of the Tukey test calculations show that pairs that have significant interactions or pairs are: (1) A1B1-A2B1, (2) A1B1-A1B2, (3) A2B1-A1B1, (4) A2B1$\mathrm{A} 1 \mathrm{~B} 2$, (5) A2B1- A2B2, (6) A1B2-A1B1, (7) A1B2-A2B1, (8) A1B2-A2B2, (9) A2B2-A2B1, (10) A2B2-A1B2, while the other pairs are stated have no difference in influence are: (1) A1B1-A2B2, (2) A2B2- A1B1.

\section{Discussion}

The Influence of Varied Passing Exercise Methods for Fixed and Changed Position to the Accuracy of Short Passing.

Based on hypothesis test it is known that the varies method of passing training fixed and changed position has a significant influence on the accuracy of short passing. The method of passing various practice positions changes better than passing practice, varying fixed positions on the accuracy of short passing. Varying passing exercises and positions change are passing exercises that are done by forming a rectangle alternately with several pairs. This exercise is almost the same as varies passing practice in fixed positions, it's just different in the position of players who are always spinning, in varies passing practice this changing position, players who pass the ball will run towards the player who receives the ball. This exercise forms a rectangle in passing by rotating clockwise. This exercise can also be used to improve the ability in passing accuracy and ball feel. The problem is that this training model is difficult to implement because the training child is always required to aim at changing goals, but this training model will increasingly make the training children motivated in doing so that the results obtained will be maximized.

"Varied practice: A practice schedule in which the same skill is rehearsed in different ways" [10]. Long pass training that effectively increases the accuracy of the long pass is a group of changing the target of long-pass training methods when compared to the group of fixed target long-pass training methods. Because the target long-pass training method changes more in football games. Through targetchanging long-pass exercises, athletes can learn to adapt to changing conditions.

Motion that occurs in sports activities are results of the stimulus that is processed brain and then responded by muscle contraction, after receiving orders from the nervous command system, which is the brain. Therefore, motion skills are always related to the internal motor system of the human body, the results can be observed as changes in the position of the limb [11]. Furthermore, the motion that is carried out repeatedly will be stored in the memory of the perpetrator who will appear at any time if there is the same stimulus. For that reason, motion skills in sports must always be repeatedly done so that they are not easily lost in memory, ensuring that the individuals remain skilled in every movement.

Capacity building that occurs due to the association of knowledge gained by the child at the previous meeting with new when performed repeatedly. This is based on the theory of learning the law of exercise proposed by Thorndike (Rahyubi, 2012: 164) which states that "the principle of the law of practice shows that the main principle in learning is repetition, the more frequently repeated, the subject matter will be increasingly mastered".

"From this perspective, most of the studies regarding schema theory have postulated that variable practice is more effective than constant practice in learning skills to be performed in unpredictable environments, or open skills" [12]. "The finding that children performed better in variable practice groups (practicing using four or five targets) as compared to constant practice groups (practicing using 1 or no specific target) supports the variability of practice" [13].

The Effect of High and Low Feet Coordination on the Accuracy of Short Passing 
The results of the analysis show that players with high ankle coordination ability are higher (better) compared to players with low ankle coordination ability to the accuracy of short passing. Accuracy toward the target is influenced by the coordination of eye and foot motion. Coordination is the ability to unite a variety of separate motion nervous systems into one efficient motion pattern. The more complex the movement is, the greater the level of coordination needed to carry out Dexterity. Coordination is closely related to the ability of other motor movements, such as balance, speed, agility. Balance is defined as the ability to maintain body posture and position in the area of support when standing (static balance) or when carrying out movements (dynamic balance) [14].

Ankle coordination is an integration between the eyes as the main function holder, in this case, seeing the ball and the game situation faced when kicking the ball and feet as the function holder who performs a movement that is, touching or kicking the ball so that it can move from its original place. The good long pass capability is influenced by the ankle coordination owned. Integration involving two parts of motion, namely the eyes and feet must be coupled into one good and harmonious movement pattern to support the accuracy of the long pass. Coordination is the ability to move with various levels of difficulty quickly and efficiently and full of accuracy. The level of coordination of one's motion is reflected in its ability to carry out a movement smoothly, precisely, quickly and efficiently. An athlete with good coordination is not only able to do a skill perfectly but also is easy and fast in carrying out new skills for him. Good coordination can change and move quickly from one movement pattern to another so that the movement becomes effective [15].

Football is a sports game with elements of movement that are quite complex. Football games generally require ankle coordination. This is because almost all football games require good coordination of subjects. The accuracy of football passing is one of football skill that demands good quality of eye and ankle coordination. In other words, the probability that the ankle coordination of a football player will affect the accuracy of football passing.

It is a known fact that foot-eye coordination skill is important in the game of football. It was confirmed at the Institute for Neurology in London that vision controls the movement of the foot. Foot-eye coordination skill allows players to make pinpoint passes, free kick with precision, fake out the defense and dribble the ball. Foot-eye coordination also allows a player to stop a soccer ball with his foot and make adjustments to intercept the ball. The development of foot-eye coordination allows a player to keep his head up during ball handling. Further, soccer requires the proper coordination of different body parts particularly the eyes, feet and the hand. Eye-hand coordination is important for goalkeepers to prevent the ball from reaching the goal posts. While field players require excellent eye-foot coordination to accurately kick the ball to the right direction. The players' eyes provide their sense of direction and their feet move to follow that projected route. Vision is used as a feed-forward control where the eyes fixate on the target position and interact with the locomotor system to plan the next movement and produce a coordinated activity. Running, kicking and ball direction then become orchestrated to reach the same "goal" [16].

Athletes who have high coordination and passing are very different from athletes who have a low level of coordination. Children who coordinate well will always gain expertise quickly and can do it smoothly, compared to children who do movements with stiffness and difficulty, a young athlete who coordinates well will spend less the same performance, therefore the results of coordination good will be more effective in a skill [7].

The interaction between Exercise Methods (Varied Fixed and Changed Positions) with Foot Coordination (High and Low)

Based on the results that have been stated in this study that there is a significant interaction between varying passing training methods fixed and changing positions and ankle coordination (high and low) to the accuracy of short passing. The results showed that groups of students who were trained to use passing training methods with varying positions changed with high ankle coordination would be better than students who had low ankle coordination, this was because of the method of varied passing training with changing positions demanding more difficult movements than groups. varying passing training methods in fixed positions. Furthermore, groups of students with low coordination will be better trained by varying fixed position passing training methods.

\section{CONCLUSIONS}

Based on the results of the research and data analysis results that have been carried out, the following conclusions are obtained. (1) There is a significant difference in the effect of varying passing training methods fixed and changed positions to the accuracy of short passing. The method of passing various practice positions changes better than passing practice, varying fixed positions on the accuracy of short passing. (2) There is a significant difference in the effect of high ankle coordination ability and low ankle coordination on the accuracy of short passing. Students who have high ankle coordination are better than low ankle coordination on the accuracy of short passing. (3) There is a significant interaction between varying passing training methods, fixed and changing positions and ankle coordination (high and low) to the accuracy of short passing.

\section{REFERENCES}

[1] C. Collet, "The possesion game? a comparative analysis of ball retention and team succes in european and international football," Journal Of Sports Scienses, Vol 1/14, 2012

[2] K. Burcak, "The effects on soccer passing skills when warming up with two different sized soccer balls," Academic Journals, Vol. 10(22), pp. 2860-2868, 2015.

[3] K. Göral, "Passing success percentages and ball possession rates of successful teams in 2014 FIFA World Cup," International Journal of Science Culture and Sport (IntJSCS), Vol 3(1), pp. 86-95, 2015.

[4] D. Adams, R. Morgans, J. Sacramento, S. Morgan, \& M. D. Williams, "Successful short passing frequency of defenders differentiates between top and bottom four English Premier League teams," International Journal of Performance Analysis in Sport, Vol 13, pp. 653-668, 2013. 
[5] Y. Nossek, Teori umum latihan. (Terjemahan M. Furqon). Logos: Pan African Press Ltd. (Buku asli diterbitkan tahun 1992), 1982.

[6] D. Milenković, \& I. Stanojević, "Accuracy in football: scoring a goal as the ultimate objective of football game," (Ijcrsee) International Journal of Cognitive Research in Science, Engineering And Education, Vol. 1, No.2, 2013.

[7] O. T. Bompa, Theory and methodology of training. Toronto: Kendall/ Hunt Publishing Company, 1994

[8] M. S. Babu, \& P. P. P. S. Kumar, Effect of continuous running fartlek and interval training on speed and coordination among male soccer players. Journal of Physical Education and Sports Management, Vol. 1, No. 1, pp. 33-41, 2014.

[9] Sukadiyanto. Pengantar teori dan metodologi melatih fisik. Bandung: CV Lubuk Agung, 2011.

[10] W. H. Edward, Motor learning and control: from theory to practice. Sacramento: California State University, 2011.
[11] J. Keogh, Sugden. Child development. New York: Macmillan Publishing Company, 1985.

[12] J. M. Francisco, M. Eva, \& Ordoño. Variability and practice load in motor learning. Revista internacional de ciencias del deporte (RICYDE), Vol. 39(11), pp. 62-78, 2015

[13] S. J. Douvis, Variable practice in learning the forehand drive in tennis. Perceptual and Motor Skills, Vol. 101, pp. 531-545, 2005.

[14] M. Sajoto, Peningkatan dan pembinaan kekuatan kondisi fisik dan olahraga. Semarang: Dahara Prize, 1995.

[15] R. Lutan, Dasar-dasar kepelatihan. Jakarta: Departemen Pendidikan Nasional, 2002

[16] W. Tiu, C. L. Salipot, C. A. Maquiraya, D. M. Burkley, M. Castaneda, \& M. G. Gomez, "Effects of a modified football program in improving foot-eye coordination among students with intellectual disability," Educational Research. Vol. 3(4) pp. 412-423, 2012. 